\title{
Helen Kohlen, Joan McCarthy (eds) (2020) Nursing Ethics: Feminist Perspectives.
}

\author{
Springer, Cham, XXIX, 187 pages, eBook 53.49€, ISBN \\ 978-3-030-49104-8
}

\section{Tijs Vandemeulebroucke}

Accepted: 26 May 2021 / Published online: 17 June 2021

(C) Springer-Verlag GmbH Deutschland, ein Teil von Springer Nature 2021

The year 2020-2021 has confronted many of us with the crucial role of nurses in different healthcare settings (e.g. hospitals, nursing homes, home care). Moreover, the COVID-19 pandemic has disclosed, in a very intense manner, the inherent ethical dimensions of nursing practices, which are grounded in the "[...] everyday relationship the nurse has with patients" (Kohlen and McCarthy, p. XIV). One needs to wonder why a crisis with the proportions of a pandemic was necessary to increase awareness of nurses' role and its ethical dimensions. Moreover, it needs to be questioned if this increased awareness will last and will lead to positive change in our conception of nursing around the world. To do this, the book Nursing Ethics: Feminist Perspectives edited by Helen Kohlen and Joan McCarthy gives us the necessary tools.

As the title indicates, the book introduces readers to nursing ethics, feminist theory, the convergences between these discourses, and their philosophical-theoretical and applied research methodologies. Along these methodologies, the book is divided into two parts, each consisting of five chapters. Holding these parts together is an interview with political scientist Joan Tronto (Tronto, p. 93-96). All ten book chapters are written by experienced researchers and lecturers in the field of medical, healthcare and/or feminist ethics, philosophy, care policy and/or law, nursing, etc.

In the first part of the book, authors develop insight into following topics: the history of nursing scholarship and education (Fowler, p. 3-21); how feminist theory has influenced nursing ethics (Peter and Liaschenko, p. 23-34); the need for nursing ethics to include a socio-political critique (Thompson, p. 35-66); the centrality of 'testimony' in nursing practices and its socio-political potentialities (Ceci, Djkowich and Petrovskaya, p. 67-81); the need of respecting cultural diversity and including

\footnotetext{
Dr. Tijs Vandemeulebroucke $(\square)$

Centre for Biomedical Ethics and Law, Department of Public Health and Primary Care, Faculty of Medicine, KU Leuven, Leuven, Belgium

E-Mail: tijs.vandemeulebroucke@kuleuven.be
} 
this diversity as an essential element in ethical nursing practice and theory (Wepa, p. 83-91).

The authors of the second part deal with following topics: the influence of organizational structures on nurses ethical behavior (Campbell, p. 99-115); how the use of principlism dismisses nurses' voices and experiences in hospital ethics committees (Kohlen, p. 117-135); the individual and societal impact of the use of digital technologies in home care practices (Peter, p. 137-148); the centrality and layeredness of the notion of 'conscience' in the practice of abortion (McCarthy and McGuinness, p. 149-169); and the potential of systematically including feminist central notions of 'power', 'vulnerability' and 'relational autonomy' in research practices (Felzmann, p. 171-187).

It is clear that the ten chapters of the book, and the included interview with Tronto, are all grounded in the fundamental emancipatory dynamic of feminist theory. Feminist critique on the structures (societal, gender, value of profession, value of care, etc.) that confine people to a particular socio-historical location in the world is meant to show that these structures are historical products of human relations and their inherent power differences. Hence, these structures are open to change and as such can be adjusted to reach a more equal and just world for everyone, an insight feminist theory only reached over time as Wepa's chapter on intercultural perspectives shows. The fact that the profession of nursing is fundamentally characterized by a multitude of relationships, makes that nurses hold great potential to contribute to this emancipatory dynamic.

It needs to be pointed out that although the book distances itself from a conception of feminist theory as feminine theory, all authors are female. One could wonder if a non-female perspective would have touched upon other topics than those taken up in the book. Additionally, taken into account Bernice Fisher's and Joan Tronto's (1990, p. 40) characterization of care as "[...] a species activity that includes everything that we do to maintain, continue, and repair our 'world' so that we can live in it as well as possible.", one could expect a chapter on nurses' responsibility regarding the natural environment we all live in, as the 'world' Fisher and Tronto (1990, p. 40) refer to "[...] includes our bodies, our selves, and our environment". It is without question that nurses' contribution to the ethical debate on the environmental impact of healthcare practices contains great potential (Kangasniemi et al. 2014).

That being said, Nursing Ethics: Feminist Perspectives is a much welcomed book and should be read by students, academics, professionals, and the broader public to gain a holistic view and deeper understanding of nursing and all its ethical dimensions.

Conflict of interest T. Vandemeulebroucke declares that he has no competing interests.

\section{References}

Fisher B, Tronto J (1990) Toward a feminist theory of caring. In: Abel EK, Nelson M (eds) Circles of care. Work and identity in women's lives. SUNY Press, Albany, pp 35-62

Kangasniemi M, Kallio H, Pietilä A-M (2014) Towards environmentally responsible nursing: a critical interpretive synthesis. J Adv Nurs 70(7):1465-1478. https://doi.org/10.1111/jan.12347 